\title{
O PROJETO "ESPORTE E ARTE: DIÁLOGOS": A CONSTRUÇÃO DE UM BANCO DE DADOS
}

\author{
Victor ANDRADE Melo* \\ Mônica Borges Monteiro, Fabio Faria Peres, \\ Carlos Augusto Santana Pereira, Linair Maria Campos, \\ Mônica Carvalho Silva, Bianca Castro Vieira, \\ Isabela Maria Azevedo Buarque Gama, Michele Cabral, \\ Cláudio Lacerda, Diogo Baptista Pereira e Juliana Garcia Ramos
}

\section{RESUMO}

O projeto "Esporte e arte: diálogos" foi criado no ano de 2003 e tem como objetivos: a) mapear obras artísticas onde o esporte é tematizado/representado; b) discutir os diálogos intersemióticos possivelmente observáveis entre esporte e diferentes manifestações artísticas; c) desenvolver estratégias didático-metodológicas construídas a partir do diálogo entre esporte e diferentes linguagens; d) discutir as representações de esporte nas obras de arte. Neste artigo, objetivamos apresentar a experiência de utilização de recursos computacionais para potencializar o alcance dos intuitos do projeto, notadamente a construção e alimentação de um banco de dados, tarefa fundamental para permitir a eficácia, efetividade e eficiência de nossas ações.

PALAVRAS-CHAVE: esporte - arte - história.

\section{INTRODUÇÃO}

A arte e a literatura são para o esporte uma sociologia indireta, uma psicanálise, um testemunho [...] A investigação da presença do esporte na arte nos interessa na medida em que nos esclarece sobre a identidade do esporte e sobre o papel do imaginário na constituição das relações esportivas [...]. O esporte não é simplesmente o indício de uma sociedade lúdica (ignorada ou tolerada), mas a sociedade lúdica percebida e descrita pelos meios da arte, em um quadro de expressão de sua valorização pela sociedade global (JEU, 1992, p.21).

$\mathrm{O}$

projeto "Esporte e arte: diálogos"1 foi criado no ano de 2003 e envolve acadêmicos e investigadores do Grupo de Pesquisa "Anima":

\footnotetext{
* As notas sobre os autores encontram-se no final deste artigo.
} 
Lazer, Animação Cultural e Estudos Culturais/EEFD/UFRJ, ${ }^{2}$ do Laboratório de Estudos do Tempo Presente/IFCS/UFRJ, ${ }^{3}$ do Instituto Virtual do Esporte/Faperj ${ }^{4}$ da Rede Cedes/UFRJ/Ministério do Esporte ${ }^{5}$ e do Núcleo de Computação Eletrônica/UFRJ. ${ }^{6}$ Possui ainda vinculações com o Programa de Mestrado em História Comparada/IFCS/UFRJ e com o Programa Avançado de Cultura Contemporânea/UFRJ. ${ }^{8}$ Trata-se, portanto, de uma rede multidisciplinar e multi-institucional de investigação.

Até os dias de hoje, o projeto conta com financiamentos da Fundação de Amparo à Pesquisa do Estado do Rio de Janeiro (Faperj; recursos financeiros do Instituto Virtual do Esporte: aquisição de material permanente e bolsas de apoio técnico e de iniciação científica), do Conselho Nacional de Desenvolvimento Científico e Tecnológico (CNPq; bolsa de produtividade, períodos 2003-2006 e 2007-2009, bolsas de apoio técnico e de iniciação científica, auxílios financeiros por meio de editais) e do Ministério do Esporte (recursos da Rede Cedes/UFRJ; aquisição de materiais e bolsas).

Quatro são os intuitos básicos e objetivos do projeto:

a) uma preocupação relacionada à memória - mapear as obras artísticas onde o esporte é tematizado/representado, construindo um banco de dados, disponibilizado na internet, acessível a pesquisadores, professores e interessados em geral;

b) uma preocupação ligada à linguagem - discutir os diálogos intersemióticos possivelmente observáveis entre esporte e distintas manifestações artísticas;

c) uma preocupação relacionada à intervenção pedagógica - desenvolver estratégias didático-metodológicas construídas a partir do diálogo entre esporte e diferentes linguagens;

d) uma preocupação histórica - discutir as representações de esporte nas obras de arte, buscando melhor entender a sua presença e o seu espaço na modernidade e na contemporaneidade.

Fundamentalmente, desejamos chamar a atenção e investigar algo que vem sendo somente parcialmente abordado em nossa produção acadêmica: os aspectos estéticos do fenômeno esportivo, contribuindo para a promoção de uma arqueologia social do objeto esporte, desvendando sua presença por entre redes, camadas e teias da sociedade. 
Neste artigo, estimulados pelo tema dessa edição da revista Pensar a Prática, objetivamos apresentar a experiência de utilização de recursos computacionais para potencializar o alcance dos objetivos do projeto "Esporte e arte: diálogos", notadamente a construção e alimentação de um banco de dados. Se observarmos os quatro intuitos que estabelecemos, facilmente verificaremos que esta é uma tarefa fundamental para permitir a eficácia, a efetividade e a eficiência de nossas ações.

Já que pretendemos contribuir e efetivamente temos contribuído para mapear a produção artística onde o esporte é tematizado/representado, isso seria de pouca valia se não conseguíssemos dar visibilidade e acessibilidade ampla ao que tem sido coletado, permitindo que outros pesquisadores possam não só desenvolver suas investigações próprias, como também contribuir com a alimentação de nosso banco, algo para o qual estamos nos preparando para um futuro próximo.

Assim, estamos argumentando que a disponibilização dos resultados de nossos esforços é central para a execução de trabalhos históricos (outro de nossos objetivos), já que os dados inseridos constituem-se nas fontes a serem utilizadas nas investigações.

Quando, em nossas experiências como dissertantes em cursos e palestras, argumentamos que as manifestações artísticas podem ser usadas para trabalharmos pedagogicamente a prática esportiva, é comum identificarmos o desconhecimento acerca dessa produção. Como podem os professores utilizar as obras de arte se a desconhecem? Assim, o banco de dados cumpre também essa função: informação para o desenvolvimento de possíveis estratégias de atuação profissional.

Pretendemos também aperfeiçoar o banco de forma que seja possível a obtenção de informações cruzadas das diferentes linguagens cadastradas. Futuramente poderá o pesquisador/interessado identificar como um mesmo tema (o futebol, por exemplo) foi trabalhado por olhares diversos, advindos de manifestações distintas. Com isso, esperamos também facilitar as investigações dedicadas à discussão dos diálogos intersemióticos.

Neste artigo, inicialmente apresentamos algumas informações sobre o projeto "Esporte e arte: diálogos", já que consideramos isso central para que o leitor entenda as intencionalidades que encaminham a construção do banco de dados. Ao fim, explicitamos as estratégias utilizadas e nossa experiência com tal recurso. 
Esperamos que tal discussão possa contribuir para abrir canais de diálogo com colegas que trabalham, nessa mesma perspectiva, o uso de recursos eletrônicos para potencializar o alcance de seus objetivos, bem como angariar sugestões e críticas que possam se constituir em contributos para nosso projeto.

\section{UM POUCO MAIS SOBRE O PROJETO "ESPORTE E ARTE: DIÁLOGOS"}

\section{A natureza da investigação}

Do ponto de vista da investigação da linguagem/fenômeno social esporte, há que se considerarem as mudanças recentes no âmbito da historiografia. Nas últimas décadas do século XX, observa-se um ampliar do conceito de fontes, antes basicamente restritas ao documento escrito. Isso certamente está relacionado às novas perspectivas abertas na esteira do surgimento e desenvolvimento, relativamente recente, da nova história cultural (BURKE, 2005).

O contexto sócio-econômico, a ascensão da cultura como dimensão fundamental no capitalismo tardio, o impacto desse processo no ocasionar de reformulações no âmbito das ciências sociais e humanas, entre outros fatores, apresentam a necessidade de busca de novas fontes, entre as quais encontramos as obras de arte.

Vejamos que aqui não estamos falando da subdisciplina "História da Arte", mas de uma articulação entre a compreensão da "arte como agente da história" (onde procuramos estudar o papel da arte no decorrer da história), da "arte como discurso sobre o passado" (como as obras representam o contexto histórico) e a "arte como testemunho do passado" (elementos do passado presentes nas obras).

Assim sendo, estamos considerando que as obras de arte tanto são portadoras de uma representação sobre o passado quanto desempenham uma função nesse percurso. Uma ressalva, todavia, merece ser feita. Nas obras, não encontramos uma "reprodução" da realidade, mas um olhar específico do artista. Logo, devem ser sempre contextualizadas, entendidas no âmbito sócio-cultural de sua produção, inseridas no movimento artístico a qual se filia, no conjunto da história do próprio artista.

340 MELO, V. A. et al. O projeto "Esporte e Arte: diálogos": a construção ... 
De qualquer forma, podemos considerar as obras de arte como potenciais fontes históricas, que podem contribuir para ampliar nosso olhar sobre a realidade e sobre o fenômeno esportivo. Por que determinados artistas representaram, de diferentes formas, o esporte em sua produção? Que intencionalidades isso carrega? Que sentidos e significados envolvem essa representação?

É considerando tais discussões que afirmamos que este estudo articula preocupações relacionadas à memória, à história e à investigação do encontro de linguagens. ${ }^{9}$

Por fim, devemos dizer que não nos alinhamos diretamente com as perspectivas abertas pela iconografia e iconologia, ainda que de forma nenhuma estejamos a negar suas contribuições. Estamos mais próximos da posição de Peter Burke (2004, p. 227), que propõe uma "terceira via":

É este enfoque que, na minha visão, promete ser o de maior valor nos próximos anos. Ele poderia ser descrito como "a história cultural da imagem", ou ainda a "antropologia histórica da imagem", uma vez que pretende reconstruir as regras ou convenções, conscientes ou inconscientes, que regem a percepção e a interpretação de imagens numa determinada cultura.

\section{A natureza pedagógica do projeto}

Do ponto de vista da intervenção pedagógica, nosso intuito é chamar a atenção para a necessidade de consideração dos aspectos estéticos na elaboração de propostas pedagógicas no âmbito da Educação Física/Ciências do Esporte.

Nos últimos anos, nossa área de conhecimento procurou se aproximar das ciências humanas e sociais, sem se afastar por completo do conhecimento biomédico que a marcou e a caracterizou desde suas origens. A despeito dos importantes avanços, questionamos: não está na hora de nos aproximarmos mais da Estética, uma disciplina filosófica, para ampliarmos nossas considerações acerca do papel do esporte na sociedade? Será que os aspectos estéticos não são também relevantes na configuração da importância, da presença social e da popularidade do esporte?

Ainda mais, se pensarmos em nossa intervenção com o esporte como uma possibilidade e um pólo de animação e mediação cultural, 
segundo Melo (2006), parece interessante nos aproximarmos das considerações pedagógicas dos autores que buscam nos Estudos Culturais inspiração para repensar o papel da educação na sociedade. E aí, as considerações acerca da Estética devem ganhar papel privilegiado na discussão.

Mas afinal, o que é estética? A estética está somente relacionada à arte? Por certo que não. Adolfo Vázquez (1999), por exemplo, lembranos de que ela está na natureza, na indústria, na nossa vida cotidiana. $\mathrm{O}$ autor ressalta a idéia de que todos nós estamos submetidos diariamente a situações estéticas, mesmo que não percebamos claramente:

Acadêmicos ou não, em determinados momentos de nossas vidas todos vivemos em uma situação estética, por mais ingênua, simples ou espontânea que seja nossa atitude como sujeitos nela. Ante a flor que se dá de presente, o vestido que se escolhe, o rosto que cativa, ou a canção que nos agrada, vivemos essa relação peculiar com o objeto, que chamo de situação estética. E a vivemos guiados por certa consciência ou ideologia estéticas (VÁZQUEZ, 1999, p. 17).

Podemos então dizer que o conceito de estética está relacionado ao conhecimento sensível, ligado às sensações, aos sentidos (visão, audição, paladar, tato, gustação), algo para o qual somos educados cotidianamente, que interfere em nossas escolhas, nossas opções, mesmo que nem sempre demos a ela a importância que deveria ter no processo educacional.

Com isso, queremos afirmar que uma das responsabilidades da intervenção pedagógica deve ser a educação das sensibilidades. Não se trata somente de educar para a construção de novos valores, mas entender que a educação estética é uma necessidade e é tão importante quanto qualquer outra perspectiva de atuação. Devemos compreender que há uma articulação entre valores e sensibilidades na formação dos sujeitos e das sociedades, daí a necessidade de uma ação articulada em ambos os âmbitos.

Se a estética não se resume à arte, esta continua a ser uma prática social importante e pode ser uma eficaz ferramenta no processo de educação das sensibilidades de nossos alunos. Assim, podemos utilizar as manifestações artísticas em nossas aulas relacionadas ao 
esporte para também implementar processos de formação estética, não só porque esta é uma dimensão importante para nossos alunos, enquanto aspecto relevante do processo educacional, como também porque permite-nos ampliar a compreensão sobre o próprio esporte, já que na arte encontramos muitos indícios de representações sociais desta prática social. ${ }^{10}$

\section{Esporte e arte: relações}

As relações entre esporte e arte devem ser compreendidas de forma multifacetada. Uma das ocorrências mais facilmente identificadas é a comparação de atletas com artistas, de belas jogadas com obras de arte ou a utilização de termos artísticos como referência a peculiaridades dos certames esportivos.

É comum que cronistas e jornalistas esportivos façam uso de expressões como:

• "futebol-arte" (em contraposição a um jogo feio, "de resultados");

• "a equipe joga por música” (quando joga unida);

- "o atleta pintou uma aquarela naquela jogada" (quando realiza uma bela jogada);

- "o jogador está fazendo cena, fazendo cinema" (quando finge algo).

Um dos cronistas brasileiros que mais fez uso desse recurso foi Nélson Rodrigues, sempre a considerar as partidas de futebol como verdadeiras óperas e a comparar os jogadores a gênios da arte, como no caso de Pelé, por ele considerado um verdadeiro Michelângelo, e como Garrincha, comparado a Charles Chaplin, pela capacidade de instaurar um ambiente alegre e desvendar o sorriso na face do torcedor.

Outra dimensão importante a ser considerada é a representação/ tematização do esporte pelas diferentes manifestações artísticas. No Brasil, isso pode ser claramente identificado:

\section{Nas artes plásticas}

Em obras de Rubem Gerschman, Cândido Portinari, Vicente Rego Monteiro e outros, entre os quais muitos ligados à arte contempo- 
rânea e à arte naif. Algumas vezes o esporte é retratado de forma direta, figurada, quando elementos da prática são claramente identificados nas obras. Em outras vezes, dimensões do esporte servem como inspiração para alguma abstração. Há ainda o caso das charges, que ganharam importante espaço nos jornais diários, onde o esporte é freqüentemente retratado, dialogando com fatos recentes da política, da economia e das relações sociais em geral.

\section{Na literatura}

Em poesias, romances, contos e crônicas, de autores como, por exemplo, Machado de Assis, Arthur Azevedo, Raul Pompéia, Carlos Drummond de Andrade, Paulo Mendes Campos, entre muitos outros.

\section{Na música}

Em letras de compositores de diferentes épocas, onde se destaca um grande número de sambas (por exemplo, de Noel Rosa, Geraldo Pereira, Chico Buarque, entre outros), mas também de outros estilos (como em recentes letras de Zeca Baleiro, dos grupos O Rappa e Skank). Há também músicas instrumentais que são produzidas a partir de uma inspiração esportiva, como o choro "1 x 0", de Pixinguinha e Benedito Lacerda (que depois recebeu letra de Nelson Angelo).

\section{Nas artes cênicas (teatro e dança)}

Onde podemos identificar, por exemplo, algumas peças de Oduvaldo Vianna Filho, Nélson Rodrigues e Dias Gomes, e coreografias de Renata Mello/Grupo Marzipan (SP), Grupo Tran Chan (BA) e Cia. Deborah Colker (RJ), entre outros.

\section{No cinema}

Em filmes de Joaquim Pedro de Andrade, Oswaldo Caldeira, Roberto Farias, Nélson Pereira dos Santos, entre outros. Em certos filmes, o esporte é o assunto central, como em Surf Adventures, de Arthur Fontes, Boleiros, de Ugo Giogetti, ou Todos os Corações do Mundo, de Murilo Salles. Em alguns ele ocupa um papel importante, mas também é utilizado como conexão para outros temas, como em Garrincha, Alegria do Povo, de Joaquim Pedro de Andrade, e em Pra Frente Brasil, de 
Roberto Farias. Em muitos outros filmes vemos apenas algumas cenas ou alguns personagens ligados ao esporte. Além de longas, há também muitos curtas-metragens que representaram dimensões do esporte. Vale também destacar que existe uma imensa produção televisiva ligada ao assunto, notadamente um grande número de documentários.

No âmbito do projeto, ainda estabelecemos outra discussão: seria o esporte uma forma de manifestação artística? Tendo em vista os deslocamentos conceituais dos dois fenômenos na contemporaneidade (esporte e arte), respondemos que sim. Mais ainda, argumentamos que normalmente trata-se de uma arte de performance com script comumente não predefinido. ${ }^{11}$

\section{ESPORTE E ARTE: DIÁLOGOS - UM BANCO DE DADOS}

O banco do projeto "Esporte e arte" é um repositório onde os dados relevantes a este domínio são mantidos e gerenciados. Esse banco possui diversas tabelas, e cada uma delas contém um conjunto de atributos sobre um aspecto relevante do projeto. Por exemplo, na tabela de artes plásticas, temos atributos tais como nome da obra, tema, código do país, entre outros.

Algumas tabelas se relacionam entre si, indicando que os dados de uma podem estar relacionados ou podem ser complementados pelos de outra. Essa estratégia de acomodar os dados em tabelas relacionadas é importante para sua melhor organização e recuperação, evitando informações redundantes.

O banco, além de conter as tabelas e seus relacionamentos, possui uma série de funcionalidades que nos permite manipular os dados de forma íntegra e segura, proporcionando uma visão integrada do que é cadastrado, e, ao mesmo tempo, disponibilizando-o de maneira eficiente a diversos usuários de maneira simultânea.

A modelagem do banco reflete as necessidades de informação do projeto de forma genérica, devendo ser aperfeiçoada na medida em que o amadurecimento de seu uso proporcione demandas mais específicas. Esperamos assim que os pesquisadores interessados explorem o banco com o seu viés atual, nos fornecendo subsídios que apontem para a necessidade de disponibilizar novos dados ou o cruzamento de dados já existentes. 
Essa interação dinâmica enriquece o mérito do banco, evidenciando de que forma os dados brutos se transformam em informação relevante, ao mesmo tempo em que pode servir de elo para a divulgação e o cruzamento de pesquisas originais feitas a partir da interpretação de seus dados.

No momento em que escrevemos esse artigo (março de 2007), já estão disponíveis dados sobre as seguintes linguagens:

a) Esporte e cinema - Brasil; América do Sul e Portugal/Espanha (para dar prosseguimento, pretendemos ampliar para todos os países da América Latina e posteriormente para países europeus; também disponibilizamos bancos internacionais já existentes, que contêm basicamente filmes norte-americanos);

b) Esporte e Artes Plásticas (dividido em geral, charge e fotografia) - Nacional e Internacional;

d) Esporte e Música - Nacional;

e) Esporte e Artes Cênicas (dividido em Dança e Teatro) - Nacional e Internacional

Já temos catalogadas 3250 obras, ${ }^{12}$ onde:

a) cinema - 538 filmes; 235 são longas-metragens nacionais, 67 são curtas-metragens nacionais, 170 são longas-metragens Latino-Americanos e 66 são longas-metragens da Espanha e Portugal;

b) artes plásticas - 2136 obras, das quais 935 são nacionais (dentre elas 383 charges) e 1201 são internacionais; entre as nacionais e internacionais há 85 fotografias;

c) música - 522 composições nacionais;

d) artes cênicas - 54 obras nacionais e internacionais, sendo 24 relacionadas à dança e 30 ao teatro.

No que se refere ao banco, nossas ações futuras terão os seguintes objetivos:

- Manter atualizados os dados e inserir um número maior de fontes em cada linguagem;

346 MELO, V. A. et al. O projeto "Esporte e Arte: diálogos": a construção ... 
- Ampliar as localidades investigadas (caso já citado do cinema);

- Implementar a curto prazo os dados de Literatura (já em andamento);

- A médio e longo prazos, inserir também: publicidade, moda, revistas em quadrinho, videogames e tudo o mais que possa contribuir para desvendar as relações entre esporte, arte e imagem;

-Além disso, seguimos buscando o aperfeiçoamento do banco, implementando melhorias na sua interface, comunicabilidade e desempenho.

Ao catalogar as obras, procuramos apresentar o maior número de informações possíveis, que possam ser úteis aos pesquisadores; isto é, além do nome da obra, do ano e do autor, também inserimos especificações técnicas, comentários e informamos a temática central abordada (o esporte representado). No caso de artes plásticas, também inserimos a imagem da obra citada. No caso de cinema, quando possível inserimos o cartaz de divulgação.

Ainda como meta para o futuro, pretendemos implementar o uso de uma taxonomia, que ajudará na recuperação de informações relevantes, sob uma determinada perspectiva. Uma taxonomia pode ser definida como uma lista estruturada que organiza assuntos de forma hierárquica, em que cada assunto pertence a apenas uma das classes que compõem a hierarquia. Atualmente vêm sendo usadas como meios de acesso a informações online, atuando como mapas conceituais dos tópicos explorados em um serviço de recuperação (GOMES, MOTTA, CAMPOS, 2006).

O banco do projeto "Esporte e arte" permitirá que os interessados naveguem por uma estrutura de termos representativos deste domínio e encontrem de maneira guiada o conhecimento que estão procurando. Seu uso oferece vantagens sobre o emprego de palavras-chave, na medida em que estas não são elaboradas com base em nenhum aporte metodológico e não se encontram agrupadas de maneira estruturada, o que faz com que se perca a visão de uma lógica de encadeamento da informação.

Essa lógica, uma vez explicitada, pode ajudar o interessado a descobrir informações relevantes de modo mais intuitivo e prático. Além disso, a taxonomia pode ser aperfeiçoada para incluir relações entre ter- 
mos, assemelhando-se a um tesauro, levando o interessado a descobrir informações relacionadas ao termo que originalmente procura, e, desta forma, enriquecer a fonte de sua pesquisa.

É importante observar, no entanto, que uma taxonomia com o propósito de recuperação de informação não reflete o conhecimento da área de esporte, pois este é mais amplo, englobando muitos conceitos para os quais não temos obras cadastradas em nosso banco. Nossa taxonomia tem o propósito de facilitar a recuperação das obras do banco segundo um viés em que o pesquisador possa ter claras as perguntas que espera responder.

Como é difícil prever todos os pontos de vista, inicialmente daremos ênfase aos aspectos genéricos ligados ao esporte, na sua representação dentro das obras de arte que temos cadastradas. Estes aspectos agrupam-se em facetas que permitem navegar através de pontos de entrada de mais alto nível, tais como: processos (ou eventos), coisas tangíveis (tais como instituições e personalidades), coisas intangíveis (tais como os tipos de esporte e as diferentes disciplinas que o representam, a saber: artes plásticas, cinema, música, literatura, dança, etc.) e, por fim, os aspectos de tempo e espaço.

Esse tipo de organização permite evidenciar mais facilmente os possíveis cruzamentos de informação, na medida em que podemos vincular dados do banco aos termos que aparecem na taxonomia, e apresentá-los na tela na medida em que o usuário percorre a sua estrutura hierárquica. Por exemplo, em relação às instituições:

- as que surgiram em uma determinada década (aspecto temporal);

- as que surgiram em um determinado local (aspecto espacial);

- as que patrocinam determinados eventos (aspecto de processo).

Em relação ao aspecto de personalidades, podemos, por exemplo, a partir da navegação em heróis de histórias em quadrinho, saber que estes aparecem em obras tais como: na charge As Melhores da Copa, de Ponciano, de 2002; na música, No ano da Copa, bota no meio, de Unidos de Lucas, de 1986; no filme Homem de 6 milhões de cruzeiros contra as panteras, de Luís Antônio Piá, de 1978.

$\mathrm{O}$ que isso evidencia? Cabe ao pesquisador descobrir. Pode não significar nada em especial, ou pode indicar algum tipo de associação 
positiva do herói com o esporte, refletida nas mais diferentes manifestações de arte ao longo do tempo.

Este é apenas um exemplo do que se pode conseguir com o entrecruzamento de informações, revelando dados que podem surpreender o usuário, tanto no aspecto temporal, como no espacial e de processo, e também no entrecruzamento destes.

Da mesma forma, como pretendemos fazer evoluir o banco de dados, o surgimento de novas pesquisas pode demandar a elaboração de outras taxonomias mais específicas, ou o aperfeiçoamento da primeira a ser construída, o que reforça a importância da interação entre os interessados e o nosso grupo de pesquisa.

A metodologia utilizada para a coleta de obras consiste em:

a) divisão das tarefas pelos membros da equipe, que foram separados por linguagens;

b) em cada linguagem adotou-se uma estratégia específica. Com o cinema, fizemos uso de dicionários de filmes ou sítios de cinematecas e de arquivos gerais sobre filmes. Com as artes plásticas, bem como com a literatura (que recentemente teve início), adotamos listas prévias de artistas e autores. Com a música, confeccionamos uma lista de termos a serem buscados nos principais acervos, sobretudo, no que se refere aos títulos e às letras. Com as artes cênicas, fizemos uso de arquivos e revistas, bem como os recursos do Google (nesse caso fazendo uso de termos);

c) o responsável pela coleta deve também inserir os dados no banco;

d) fazemos constantemente uma "varredura" no banco, devido à necessidade de verificação constante dos dados cadastrados, já que muitas vezes as informações disponibilizadas são incompletas (dentro das categorias que elegemos);

e) são realizadas reuniões periódicas para sanar dúvidas e verificar dubiedades, imprecisões e demais problemas.

Um dos nossos maiores desafios é selecionar o que devemos catalogar. Como lidar com as obras abstratas? Um quadro que possui um carro passando em alta velocidade é ou não uma representação de automobilismo? Aliás, automobilismo é esporte? A princípio trabalhamos com o 
conceito de campo esportivo de Pierre Bourdieu (1983), mas verificamos que se nos mantivéssemos restritos a tal definição, acabaríamos por perder informações preciosas. Além disso, na hora de selecionar a obrar, verificamos que muitas vezes era possível sanar as dúvidas pelo tipo ou contexto de produção da obra, ainda que isso nem sempre fosse possível.

Assim sendo, devemos destacar que temos procurado resgatar e inserir as obras no banco a partir de uma compreensão ampliada de esporte, já que é preferível pecar pelo excesso a pecar pela falta. Além disso, não podemos prever com precisão os interesses futuros dos pesquisadores. Por exemplo, uma breve cena em um filme pode no futuro servir para que um investigador teça importantes considerações sobre seu objeto de estudo. Parece-nos mais prudente, portanto, inserir o maior número possível de obras (havendo dúvidas, cadastramos), deixando que os investigadores selecionem o que thes interessa.

Para dar conta desse desafio, com exceção do cinema latino-americano (em virtude de limites de acesso a fontes ${ }^{13}$ ), classificamos todas as obras em três diferentes listas:

Lista A - obras onde o esporte é assunto central ou de grande importância;

Lista B - obras onde o esporte ocupa lugar de relativa importância;

Lista $\mathrm{C}$ - obras onde o esporte só é citado de forma superficial ou parcial.

Com isso, ao menos minimizamos os problemas encontrados e sentimo-nos um pouco mais seguros na realização de nossas tarefas.

\section{A GUISA DE CONCLUSÃO}

Muitos problemas e desafios de ordem operacional poderiam ser apontados como fatores dificultadores para que possamos atingir nossos objetivos. Por exemplo, as nem sempre adequadas condições do fluxo de rede, o que se articula com as deficiências em termos de hardware que atinge alguns de nossos pesquisadores.

Outro problema é a provisoriedade da equipe. Com o grupo atual já trabalhamos há cerca de um ano, mas é comum a entrada e o desliga- 
mento de membros em função de término de bolsas, graduação, perda de interesse, entre outros. Por isso, sentimos a necessidade de uma formação contínua dos pesquisadores, que em níveis diferentes de sensibilização produzem quantitativamente em números distintos. Buscamos também estabelecer rotinas de trabalho, de forma a facilitar a entrada e o trabalho de novos colegas.

Mesmo a experiência de trabalhar em rede nem sempre é de fácil assimilação por todos, dialogando mesmo com as peculiaridades dos momentos de vida de cada um. O ritmo e a qualidade do cumprimento das tarefas são muito variáveis. Além do mais, possuímos uma equipe multiprofissional, o que torna desafiador o diálogo.

Vale destacar que as duas profissionais de informática que integram nosso grupo não são apenas técnicas, mas também pesquisadoras em suas áreas de conhecimento e outras afins, como a área da Ciência da Informação, o que nos fornece o aporte metodológico para a construção de taxonomias e da gestão da informação em um sentido mais amplo do que o da simples construção de um banco de dados. A troca de experiências com profissionais desta área, com formação voltada para a organização da informação, tem nos permitido a realização de pesquisas que resultam não só na assimilação de novas perspectivas, como também em uma aproximação do discurso do outro, minimizando os problemas de entendimento decorrentes da característica multidisciplinar de nosso diálogo (CAMPOS, 2006).

Obviamente temos consciência de que este projeto se trata de um trabalho de longa duração e em certo sentido inesgotável, pois sempre surgirão novas obras a serem inseridas, antigas emergirão e novas descobertas apresentarão futuros desafios.

Contudo, ainda que com esse grande número de elementos problemáticos, julgamos que nossa experiência já apresenta perspectivas alvissareiras, o que pode ser expresso no número crescente de estudos produzidos tendo a arte como fonte (seja no âmbito de nossa equipe ou por outros pesquisadores, alguns dos quais fazem uso de nosso banco) e mesmo de experiências pedagógicas em andamento, algo também progressivamente cada vez mais observável.

Muito há a ser feito, muitos rumos estão sendo e serão corrigidos, mas já podemos comemorar o fato de que, mundialmente, nenhuma experiência de bancos que tenham obras de arte como dados tem o al- 
cance da nossa. Já existem bons bancos, por exemplo, de certos museus europeus. Ou de filmes norte-americanos. Mas hoje, inclusive internacionalmente, somente nós possuímos um banco multilinguagens. Ainda mais, no que se refere à relação entre esporte e arte, só nosso banco disponibiliza dados de países da América Latina.

The "Sport and Art: Dialogues" project: the building of a database

\begin{abstract}
The "Sport and Art: Dialogues" project was created in 2003 and has, as its main aims: a) to map out art work in which sport is depicted or represented; b) to discuss the intersemiotic dialogues that can possibly be observed between sports and different artistic manifestations; c) to develop didactic and methodologic strategies built from the dialogue between sports and other languages; d) to discuss the representations of sports in works of art. In this essay, we have aimed at presenting results from the experience of using computer resources to extend the range of the project's aims, notably the building and feeding of a databank, which is considered a fundamental task in allowing for the efficacy, effectiveness, and efficiency of our actions.

KEYWORDS: sports - arts - history
\end{abstract}

El proyecto "Deporte y Arte: diálogos": la construcción de un banco de dados

\title{
RESUMEN
}

El proyecto "Deporte y arte: diálogos" fue creado en 2003 y tiene por objetivo: a) catalogar obras artísticas donde el deporte es tematizado/representado; b) discutir los diálogos intersemióticos posiblemente observables entre deporte y diferentes manifestaciones artísticas; c) desarrollar estrategias didáctico-metodológicas construidas a partir del diálogo entre deporte y diferentes lenguajes; d) discutir las representaciones de deporte en las obras de arte. En este artículo, objetivamos presentar la experiencia de utilización de recursos computacionales para potencializar el alcance de las intuiciones del proyecto, notadamente la construcción y alimentación de un banco de datos, tarea fundamental para permitir la eficacia, efectividad y eficiencia de nuestras acciones.

PALABRAS-CLAVE: deporte - arte - historia.

\section{NOTAS SOBRE OS AUTORES}

* Victor Andrade Melo - Professor da Universidade Federal do Rio de Janeiro.

- Mônica Borges Monteiro - Bolsista de Apoio Técnico/ Instituto Virtual do Esporte/Faperj, PPGE/Universidade Federal do Estado do Rio de Janeiro. 
- Fabio Faria Peres - Bolsista de Doutorado/ Fundação Oswaldo Cruz, PPGSP/ Escola Nacional de Saúde Pública/Fundação Oswaldo Cruz.

- Carlos Augusto Santana Pereira - Bolsista de Apoio Técnico/ Instituto Virtual do Esporte/Faperj, IFCS/Universidade Federal do Rio de Janeiro.

- Linair Maria Campos - Membro do Núcleo de Computação Eletrônica da Universidade Federal do Rio de Janeiro.

- Mônica Carvalho Silva - Membro do Núcleo de Computação Eletrônica/Universidade Federal do Rio de Janeiro.

- Bianca Castro Vieira - Integrante da Rede Cedes/UFRJ/Rio de Janeiro/Ministério do Esporte, Grupo de Pesquisa "Anima"/Universidade Federal do Rio de Janeiro.

- Isabela Maria Azevedo Buarque Gama - Integrante da Rede Cedes/UFRJ/Rio de Janeiro/Ministério do Esporte, PPGHC/Universidade Federal do Rio de Janeiro.

- Michele Cabral - Integrante da Rede Cedes/UFRJ/Rio de Janeiro/Ministério do Esporte, PPGHC/Universidade Federal do Rio de Janeiro.

- Cláudio Lacerda - Bolsista de Iniciação Científica/PIBIC/UFRJ/CNPq, EEFD/Universidade Federal do Rio de Janeiro.

- Diogo Baptista Pereira-Bolsista de Apoio Técnico/CNPq, IFCH/Universidade Federal Fluminense.

- Juliana Garcia Ramos - Bolsista de Iniciação Científica/PIBIC/UFRJ/CNPq, IFCS/Universidade Federal do Rio de Janeiro.

\section{NOTAS}

1 Para mais informações consulte o site da Anima: lazer, animação cultural e estudos culturais, coordenado pelo Prof. Dr. Victor Andrade de Melo. Disponível em: $<$ http://www.anima.eefd.ufrj.br/esportearte/>. Acesso em: 20 jul. 2007.

2 http://www.lazer.eefd.ufrj.br/.

3 http://www.tempopresente.org/index.php.

4 http://www.ceme.eefd.ufrj.br/ive/.

5 http://www.lazer.eefd.ufrj.br/redecedes/.

6 http://www.nce.ufrj.br/.

7 http://www.hcomparada.ifcs.ufrj.br/.

8 http://www.pacc.ufrj.br/. 
9 Exemplos de estudos dessa natureza já desenvolvidos: MELO, Victor Andrade de, VAZ, Alexandre Fernandes. Cinema, Corpo, Boxe: reflexões sobre suas relações e notas sobre a questão da construção da masculinidade. ArtCultura, Uberlândia, v.8, n.12, 2006; MELO, Victor Andrade de. Eficiência x Jogo de Cintura: Garrincha, Pelé. Nélson Rodrigues e a construção da identidade nacional . In: SILVA, Francisco Carlos Teixeira, SANTOS, Ricardo Pinto. Memória Social do Esporte: futebol e política. Rio de Janeiro: Mauad, 2006; MELO, Victor Andrade de, MONTEIRO, Mônica Borges. A presença do esporte nas artes plásticas brasileiras: diálogos com o novo realismo. Anais do X Congresso Brasileiro de História do Esporte, Lazer, Educação Física e Dança. Curitiba, 2006; MELO, Victor Andrade de, PERES, Fabio de Faria. Lazer, esporte e cultura urbana na transição dos séculos XIX e XX: conexões entre Paris e Rio de Janeiro. Logos, Rio de Janeiro, ano 12, n. 22, 2005. MELO, Victor Andrade de. A presença do esporte e do lazer em obras de arte: uma análise comparada de impressionistas e futuristas. Fênix - revista de História e Estudos Culturais, Uberlândia, v. 3, n. 3, ago./set. 2006.

10 Exemplos dessa nossa perspectiva de atuação podem ser encontrados nos estudos: MELO, Victor Andrade de. Esporte e arte. In: MINISTÉRIO DO ESPORTE. Manifestações do Jogo. Brasília: Ministério do Esporte/UNB, 2005; e MELO, Victor Andrade de. A animação cultural: conceitos e propostas. Campinas: Papirus, 2006.

11 Aprofundamos tais discussões em: MELO, Victor Andrade de. Cinema e esporte: diálogos. Rio de Janeiro: Aeroplano, 2006.; e MELO, Victor Andrade de. Esporte e arte: diálogos entre (duas?) linguagens. Movimento, Porto Alegre, v. 11, n. 2, maio-ago. 2005.

12 Pesquisa realizada em 12 de março de 2007.

13 No caso do cinema argentino, foi possível manter as listas.

\section{REFERÊNCIAS}

BOURDIEU, P. Como é possível ser esportivo? In: . Questões de sociologia. Rio de Janeiro: Marco Zero, 1983. 
BURKE, P. Testemunha ocular: história e imagem. Bauru: EDUSC, 2004.

BURKE, P. O que é história cultural? Rio de Janeiro: Jorge Zahar, 2005.

CAMPOS, M. L. de A. et al. Estudo comparativo de softwares de Tesauro. Perspectivas em Ciência da Informação, Belo Horizonte, v. 11, n. 1, 2006. Disponível em: $<$ http://www.scielo.br/scielo.php?script=sci_art text\&pid=S141399362006000100006\&lng=es\&nrm=iso $>$. Acesso em: 12 abr. 2007

GOMES, H. E.; MOTTA, D. F.; CAMPOS, M. L. de A. Revisitando Ranganathan: a classificação na rede. Biblioteconomia, Informação \& Tecnologia da Informação, 2006. Disponível em: <http://www.conexaorio.com/biti/revisitando/revisitando.htm>. Acesso em: 12 abr. 2007

JEU, B. Analyse du Sport. Paris: PUF, 1992.

MELO, V. A. de. A animação cultural: conceitos e propostas. Campinas: Papirus, 2006.

VÁZQUEZ, A. S. Convite à estética. Rio de Janeiro: Civilização Brasileira, 1999.

Recebido: 18 de março de 2007

Aprovado: 16 de abril de 2007

Endereço para correspondência: victor.a.melo@uol.com.br 